\title{
Is There a Difference between the Preoperative and Postoperative Serum Levels of Interleukin-6 and Tumor Necrosis Factor- $\alpha$ in Children Submitted to Adenotonsillectomy?
}

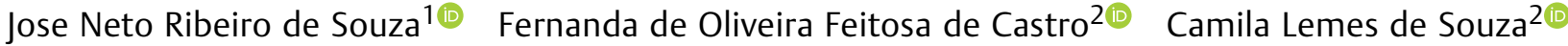 \\ Mikhael Romanholo El Cheikh ${ }^{10}$ Hugo Valter Lisboa Ramos ${ }^{3 \oplus}$ Simone Gonçalves da Fonseca ${ }^{2 \odot}$ \\ Claudiney Candido Costa ${ }^{3}$ \\ ${ }^{1}$ Department of Otorhinolaryngology, Universidade Federal de Goiás, \\ Goiânia, GO, Brazil \\ 2 Institute of Tropical Pathology and Public Health, Universidade \\ Federal de Goiás, Goiânia, GO, Brazil

\begin{abstract}
Address for correspondence Mikhael Cheikh, Master Student, Universidade Federal de Goias, R. 235, S/n - Setor Leste Universitário, Goiânia, GO, 74605-050, Brazil (e-mail: mikhaelromanholo@hotmail. com).
\end{abstract}

3 Otorhinolaryngology, Centro de Reabilitação e Readaptação Dr. Henrique Santilo (CRER), Goiânia, GO, Brazil

Int Arch Otorhinolaryngol 2022;26(2):e208-e212.

\begin{abstract}
Keywords

- chronic tonsillitis

- tonsillar hypertrophy

- adenotonsillectomy

- cytokines
\end{abstract}

Introduction Palatine and pharyngeal tonsils are the first line of defense against pathogens. Clinically, two alterations may require surgical removal of the tonsils: hypertrophy and recurrent tonsillitis. The two conditions probably result from a dysfunction of the immune system.

Objective To evaluate possible differences in the plasma levels of tumor necrosis factor- $\alpha$ (TNF- $\alpha$ ), interleukin-6 (IL-6), and interleukin-10 (IL-10) in patients submitted to adenotonsillectomy.

Methods Prospective, longitudinal study with 25 children undergoing adenotonsillectomy separated into 3 different groups: recurrent tonsillitis (RT), composed of 7 patients; recurrent hypertrophy tonsillitis (RTTH), with 8 patients; and the tonsillar hypertrophy (TH) group, with 10 patients. Ten healthy control children (SD) were also included in the study. Peripheral blood was collected, and plasma was separated to measure the levels of TNF- $\alpha$, IL- 6 , and IL-10. The Mann-Whitney test was used for statistical analysis.

Results The plasma level of IL-6 was higher in the RT $(p=0.0394)$ and TH $(p=0.0009)$ groups, compared with the control group. The TH group also had higher levels of IL- 6 than the RT group $(p=0.039)$. The IL-6/IL-10 ratio was higher in the RT $(p=0.029)$ and TH $(p=0.0005)$ groups compared with the control group. Between the RT and RTTH groups, the IL-6/IL-10 ratio was higher in the RT group, with a statistically significant difference $(p=0.0091)$.

Conclusion Patients with a history of chronic tonsillitis had higher levels of IL-6, compared with the control group. received

August 24, 2020

accepted

December 20, 2020

published online

August 19, 2021
DOI https://doi.org/ 10.1055/s-0041-1730301 ISSN 1809-9777.

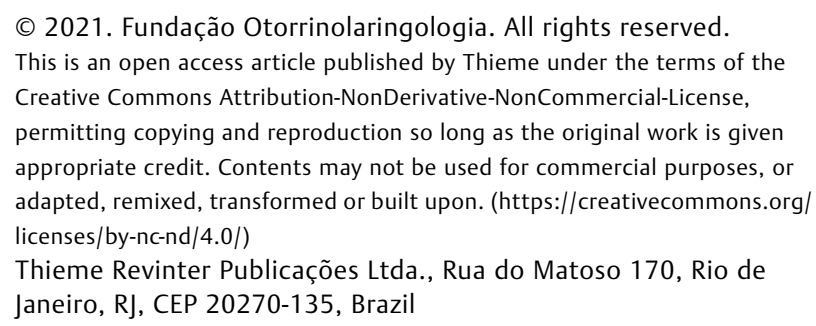

(c) 2021. Fundação Otorrinolaringologia. All rights reserved. This is an open access article published by Thieme under the terms of the Creative Commons Attribution-NonDerivative-NonCommercial-License, permitting copying and reproduction so long as the original work is given appropriate credit. Contents may not be used for commercial purposes, or adapted, remixed, transformed or built upon. (https://creativecommons.org/ licenses/by-nc-nd/4.0/) Thieme Revinter Publicações Ltda., Rua do Matoso 170, Rio de Janeiro, RJ, CEP 20270-135, Brazil 


\section{Introduction}

The tonsils form part of the mucosa-associated lymphoid tissue (MALT), in particular the nasopharynx-associated lymphoid tissue (NALT), and are rich in B and T lymphocytes, which are core components of the immune system. ${ }^{1-4}$ The tonsil's histological structure is, therefore, closely related to its immunological role. In children, the density of lymphocytes in the tonsils is greater than in adults, ${ }^{5}$ with T-cells (helper and cytotoxic) and B cells being greatly increased when the tonsils are affected by pathological processes. ${ }^{6}$

There are two main clinical manifestations of an affected tonsil: tonsillar hypertrophy and recurrent tonsillitis. ${ }^{7}$ In cases of hypertrophy, the tonsils increase in size, with no signs of inflammation, the main symptom being obstruction of the upper airways like in obstructive sleep apnea syndrome (OSAS), characterized by repetitive upper airway occlusion that causes intermittent hypoxia. Conversely, tonsillitis presents as an infectious/inflammatory process, often caused by viral or bacterial agents. These infections trigger local and systemic reactions that are often mediated by cytokines. ${ }^{8}$

Cytokines are produced in a cascade by various types of cells at the site of the lesion, that is, a cytokine may stimulate its target cells to produce more cytokines. These substances bind to specific receptors, activating intracellular messengers that regulate gene transcription. They affect the activity, differentiation, proliferation, and survival of different cells, including the cells of the immune system, and also regulate the production and activity of other cytokines. Some cytokines may exert proinflammatory (Th1 profile) or antiinflammatory activities (Th2 profile) according to the microenvironment in which they are located. Those considered proinflammatory include IL- 6 and TNF- $\alpha$, while those considered antiinflammatory include IL-10. ${ }^{9,10}$

Under antigenic stimulation, the intraepithelial $\mathrm{T}$ lymphocytes present in the tonsillar crypts produce Th1 proinflammatory and Th2 antiinflammatory responses. The proinflammatory Th1 cytokines that are then released include interleukin-2 (IL-2), interferon- $\gamma$ (IFN- $\gamma$ ), and tumor necrosis factor- $\alpha$ (TNF- $\alpha$ ). The antiinflammatory Th2 cytokines include IL-4, IL-5, IL-6, and IL-13. All of these cytokines can be measured in peripheral blood. ${ }^{11}$ The production of Th1 cytokines is dominant in immunocompetent patients. In acute tonsillitis, either viral or bacterial, the production of cytokines begins with type Th1, including IFN- $\gamma$ and TNF- $\alpha$, and later progresses to the secretion of Th2 cytokines. This allows a balance to be reached in the defense against external agents, with subsequent control of the immunological response to ensure that the inflammatory process does not perpetuate. ${ }^{12,13}$

A significant increase in the levels of the inflammatory cytokines IL- 6 and TNF- $\alpha$ was found in patients with chronic tonsillitis compared with a healthy control group. ${ }^{14}$ Tumor necrosis factor $\alpha$ and IL- 6 are considered potent inflammatory cytokines, since they play an important role in the acute phase of the inflammation. The quantification of these cytokines allows the extent of the inflammation to be calculated. ${ }^{13}$

Therefore, the objective of the present study was to evaluate possible differences in the plasma levels of TNF- $\alpha$, IL-6, and IL-10 in patients submitted to adenotonsillectomy with clinical conditions of tonsillar hypertrophy and recurrent tonsillitis, either alone or in combination.

\section{Methods}

\section{Ethical Aspects and the Study Population}

The institute's internal review board approved the protocol of this prospective, longitudinal study under reference CAAE 28210014.1.0000.5078. The parents or guardians were given information on the study, and those willing to allow their children to participate read and signed the informed consent form. The children who were able to read signed an assent form.

Children receiving care at the otorhinolaryngology outpatient clinic at Hospital das Clínicas/Universidade Federal de Goiás, between January 2015 and January 2017, who were to undergo tonsillectomy or adenotonsillectomy due to tonsillar hypertrophy and were complaining of obstruction of the upper airways with rhonchi and/or breathing through the mouth or because of recurrent infection of the tonsils, were admitted to the study. Children with any other comorbidity were excluded. The patients were distributed into three different groups according to their clinical symptoms, medical history of tonsil infections, and the size of the tonsils. $^{11}$

Group 1 - Recurrent tonsillitis (RT): Tonsil size grade I or II in children with a history of recurrent tonsillitis and at least 3 episodes/year for 3 consecutive years, or at least 5 episodes/year for 2 consecutive years, or more than 6 episodes of tonsillitis within a single year.

Group 2 - Recurrent tonsillitis with hypertrophy (RTTH): Hypertrophied tonsils grade III or IV according to the Brodsky grading scale, associated with recurrent infections.

Group 3 - Tonsillar hypertrophy (TH): Tonsil grade III or IV with no history of infection of the tonsils.

Group 4 - Control: No history of upper respiratory tract infection or adenotonsillar hypertrophy.

\section{Peripheral Blood Sample Collection}

A 3-ml sample of peripheral blood was collected into ethylenediaminetetraacetic acid (EDTA) vacuum tubes for both patients and controls. In the case of the patients, that sample was taken immediately prior to the surgical procedure and a second sample was collected 4 to 6 months after the surgery. The blood samples were sent to the immunoregulation laboratory of the Institute of Tropical Pathology and Public Health to measure cytokine levels.

\section{Preparation of the Samples}

After centrifuging the blood samples at $2,000 \mathrm{rpm}$ for 7 minutes, the separated EDTA plasma was frozen at $-80^{\circ} \mathrm{C}$ until measurement of the cytokine levels. 


\section{Cytokine Level Measurement}

The levels of IL-6 and IL-10 were measured in plasma using the immunoenzymatic method called enzyme-linked immunosorbent assay (ELISA) (BD Bioscience, San Diego, CA, USA) in accordance with the manufacturer's instructions. Readings were performed using a Multiskan microplate spectrophotometer (Thermo LabSystems, Milford, MA, USA) at a $450 \mathrm{~nm}$ wavelength. The range of detection of the IL-6 kit used was 4.68 to $300 \mathrm{pg} / \mathrm{mL}$, while the range of the IL-10 kit was from 7.8 to $500 \mathrm{pg} / \mathrm{mL}$.

The TNF- $\alpha$ cytokine was measured using the Human TNF$\alpha$ Standard ABTS ELISA Development Kit (Peprotech, Cranbury, NJ, USA) in accordance with the manufacturer's instructions. After 25 minutes, optical density was read using the Multiskan microplate spectrophotometer (Thermo Labsystems, USA) at $405 \mathrm{~nm}$, using the $620 \mathrm{~nm}$ filter as reference wavelength. The detection range of the test was 62.5 to 4,000 $\mathrm{pg} / \mathrm{mL}$.

\section{Statistical Analysis}

The data were analyzed using the GraphPad Prism statistical program, version 5.0. (GraphPad Software, San Diego, CA, USA). Medians were calculated and presented as a horizontal line. The groups were compared using the nonparametric Mann-Whitney U-test. Statistical significance was defined as $p<0.05$.

\section{Results}

Sociodemographic Characteristics of the Study Groups The overall study sample consisted of 35 children of 2 to 14 years of age (mean 7.04 years). Fourteen of the children were female and 21 were male. The RT group consisted of 7 patients, the RTTH group of 8 , and the TH group of 10 . Another 10 children formed the healthy control group (-Table 1).

\section{Cytokine Profile in the Plasma of the Individuals Included in the Study}

No statistically significant difference was found in the plasma levels of TNF- $\alpha$ between any of the study groups in relation to the control group ( $\mathbf{- F i g . ~ 1 A ) . ~ T h e ~ p l a s m a ~ l e v e l s ~}$
Table 1 Characteristics of the patients according to study group

\begin{tabular}{|l|l|l|l|l|}
\hline $\begin{array}{l}\text { Study } \\
\text { group }\end{array}$ & Females & Males & $\begin{array}{l}\text { Age } \\
(\text { mean } \pm \text { SD) }\end{array}$ & $\begin{array}{l}\text { Total number } \\
\text { of individuals }\end{array}$ \\
\hline RT & 3 & 4 & $7.8 \pm 2.5$ & 7 \\
\hline RTTH & 3 & 5 & $6.5 \pm 1.5$ & 8 \\
\hline TH & 4 & 6 & $6.9 \pm 3.1$ & 10 \\
\hline Control & 4 & 6 & $10.0 \pm 3.0$ & 10 \\
\hline
\end{tabular}

Abbreviations: RT, recurrent tonsillitis; RTTH, Recurrent tonsillitis with hypertrophy; SD, standard deviation; TH, tonsillar hypertrophy.

of IL- 6 were higher in the RT ( $p=0.0394)$ and TH ( $p=0.0009)$ groups compared with the control group. The levels of IL-6 were also higher in the TH group compared with the RTTH group $(p=0.0394)$ ( - Fig. 1B). No statistically significant difference was found in the plasma levels of IL-10 between any of the study groups in relation to the control group (-Fig. 1C).

There was no statistically significant difference in the TNF- $\alpha / \mathrm{IL}-10$ ratio between any of the groups in the present study (-Fig. 2A). The IL-6/IL-10 ratio was greater in the RT $(p=0.0293)$ and TH groups $(p=0.0005)$ compared with the control group ( - Fig. 2B). Between the RT and RTTH groups, the IL-6/IL-10 ratio was greater in the RT group $(p=0.0091)$ (-Fig. 2B).

In the patients to be submitted to adenotonsillectomy, the samples taken preoperatively did not differ from those collected 4 to 6 months after the surgical procedure (late postoperative period) with respect to the plasma levels of TNF- $\alpha(\sim$ Fig. 3A) $(p=0.2799)$, IL-6 ( - Fig. 3B $)(p=0.9684)$, or IL-10 ( - Fig. 3C) $(p=1.000)$.

\section{Discussion}

The present prospective study sought to evaluate the plasma levels of the TNF- $\alpha$, IL- 6 , and IL-10 cytokines in patients submitted to adenotonsillectomy due to tonsillar hypertrophy and/or recurrent tonsillitis, both preoperatively and postoperatively.
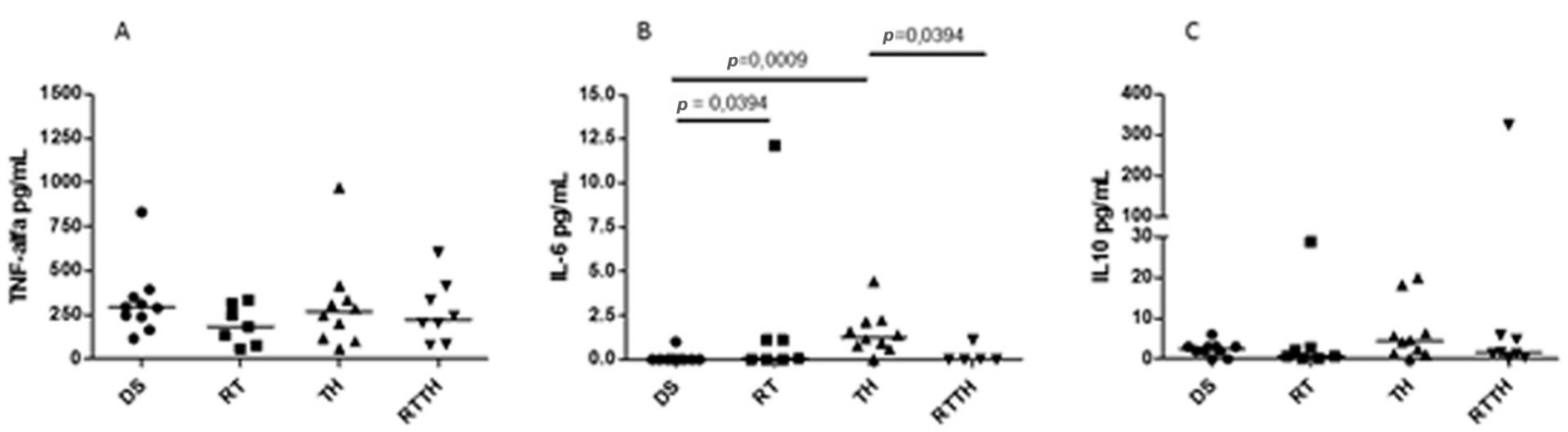

Fig. 1 Plasma levels of TNF- $\alpha$ (A), IL-6 (B) and IL-10 (C) to each group in the present study (preoperatively). Plasma levels of TNF- $\alpha$, IL-6 and IL-10 were quantified in the recurrent tonsillitis (RT), tonsillar hypertrophy (TH), recurrent tonsillitis with hypertrophy (RTTH) and controls (DS) groups by the ELISA method. The horizontal bars indicate medians. The Mann-Whitney statistical method was used and values less than 0.05 were considered significant. 
A

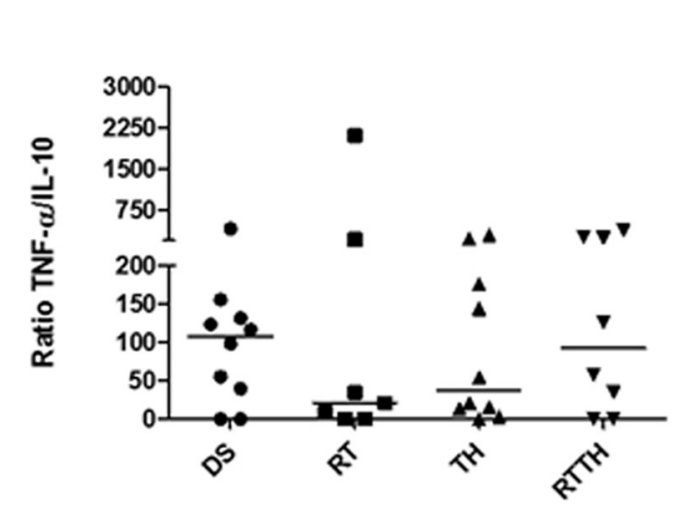

B

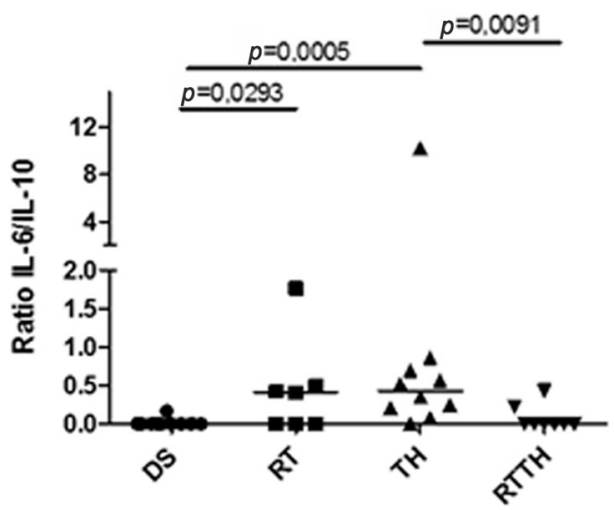

Fig. 2 Ratio between plasma levels of TNF- $\alpha$ (A) and IL-6 (B) in relation to IL-10. Plasma levels of TNF- $\alpha$, IL-6 and IL-10 were quantified in the recurrent tonsillitis (RT), tonsillar hypertrophy (TH), recurrent hypertrophy tonsillitis (RTTH) and healthy controls (DS) groups by the ELISA method. The ratios of pro-inflammatory and anti-inflammatory cytokine concentrations were calculated for each individual in each group. The horizontal bars indicate the medians. The Mann-Whitney statistical method was used and values less than 0.05 were considered significant.

A

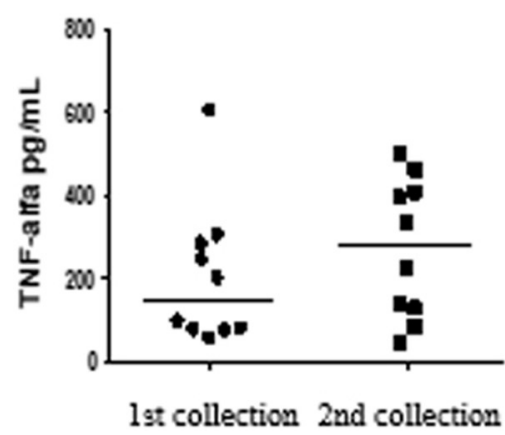

B

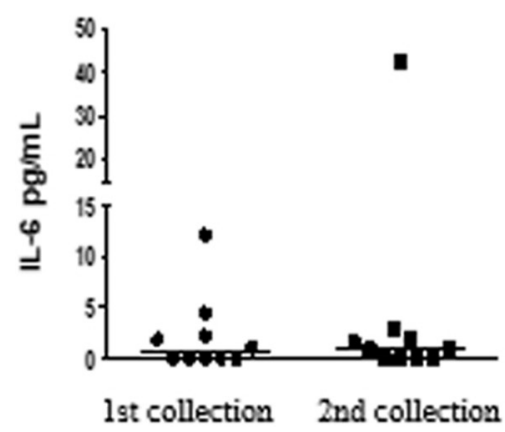

C

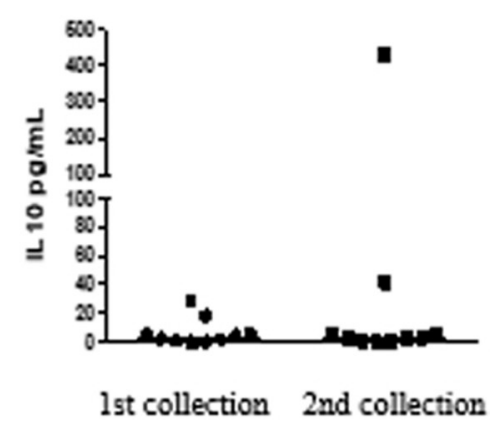

Fig. 3 Plasma levels of TNF-a (A), IL-6 (B) and IL-10 (C), in preoperatively (1st collection) and postoperatively (2nd collection) between 4 and 6 months after the surgery. No significant difference. The horizontal bars indicate the medians. The Mann-Whitney statistical method was used and values less than 0.05 were considered significant.

The tonsils and adenoids are the first line of defense against pathogenic agents in the host. Located in the upper aerodigestive tract, these structures act through both humoral and cell immunity. Clinically, there are two situations in which the surgical removal of the tonsils may be necessary: hypertrophy and recurrent tonsillitis. ${ }^{15}$ Both conditions exert a negative effect on patients' quality of life and health and, when indicated, surgery to remove the tonsils represents a good solution for improving the child's quality of life. ${ }^{15,16}$

The present results showed higher IL-6 levels in the RT and TH groups. There was a significant increase in inflammatory cytokine IL-6 levels in the patients with chronic tonsillitis compared with the healthy control group. Together with TNF- $\alpha$, IL- 6 is considered to be one of the most potent antiinflammatory cytokines, since it exerts an important role in the acute phase of inflammation, such as in the differentiation of lymphocytes, cell proliferation, and survival, and in potentiating apoptotic signaling. The measurement of these cytokine levels allows the extent of the inflammation to be estimated. ${ }^{15}$
Interleukin- 6 is secreted by many different types of cells including macrophages, monocytes, eosinophils, hepatocytes, and glial cells, with TNF- $\alpha$ and IL-1 being potent inducers of this cytokine. Interleukin- 6 causes fever and activates the hypothalamic-pituitary-adrenal axis through its $\alpha$-receptors (IL-6R $\alpha$ ) and the gp130 subunit (glycoprotein 130, member of the class I cytokine receptor family). ${ }^{17}$ As a proinflammatory cytokine, IL-6 promotes neutrophil maturation and activation, macrophage maturation, and differentiation/maintenance of cytotoxic $\mathrm{T}$ lymphocytes and natural killer (NK) cells. In addition, it activates astrocytes and microglia and regulates the expression of neuropeptides following neural lesion, contributing to regeneration. ${ }^{18}$

In the RT group, the increase in IL-6 levels could be the result of repeated stimulation by pathogenic agents, with this increase occurring 24 hours after the contact of these agents with the host. ${ }^{19,20}$

In the HT group, the increase in IL-6 levels could be the result of OSAS, a pathological condition that can elevate the serum levels of inflammatory cytokines, including IL-6. The intermittent hypoxia increases oxidative stress and 
generates reactive oxygen species (ROS), which activates oxidant-sensitive transcription factors. ${ }^{21}$ One of them is nuclear factor kB (NF-kB), which is known to induce many proinflammatory cytokines, including IL- $6 .^{22}$

In the present study, the ratios of the serum levels of the inflammatory/antiinflammatory cytokines were determined. The IL-6/IL-10 ratio was higher in the RT and TH groups compared with the control group, which is justifiable, since there is an increase in proinflammatory activity in relation to anti-inflammatory activity, increasing the ratio between the interleukins. There was a significant increase in the levels of inflammatory cytokines IL- 6 in the patients with recurrent tonsillitis compared with the healthy control group. The higher IL-6/IL-10 ratio in the RT and TH groups represents the predominant inflammatory profile in the plasma of these patients.

Both hypertrophy and the presence of recurrent infections in the tonsils are probably due to immune system dysfunction. An abnormal regulatory mechanism in lymphocyte activation must cause these deviations in the function of the tonsils, which then go on to harm the individual, leading to the need for their surgical removal. ${ }^{17,18}$

No statistically significant differences were found in the TNF- $\alpha$ levels between the study groups, as previously shown in some studies. ${ }^{14,23}$ Tumor necrosis factor- $\alpha$, also known as cachetin, is a proinflammatory cytokine produced mainly by monocytes, macrophages, and $\mathrm{T}$ lymphocytes. Following a surgical procedure, trauma or during infections, TNF- $\alpha$ is one of the earliest and most potent mediators of inflammatory response. It triggers important metabolic and hemodynamic changes and is able to activate different cells to produce other cytokines. ${ }^{7,9}$ Some studies have reported serum TNF- $\alpha$ values 10 to 20 times higher than normal in patients with chronic tonsillitis, with TNF- $\alpha$ production being higher, particularly in patients with recurrent tonsillitis. ${ }^{24}$ In the present study, blood sampling was not performed during the acute phase of tonsillitis, either preoperatively or in the late postoperative period. This fact could explain the absence of any statistically significant difference between the groups in relation to TNF- $\alpha$ levels. Nonetheless, another explanation may lie in the small sample size.

\section{Conclusion}

Patients with a history of chronic tonsillitis, in particular those allocated here to the RT and TH groups, showed higher levels of IL-6 plasma when compared with healthy controls, highlighting a more inflammatory profile in these patients.

\section{References}

1 Lee H, Ruane D, Law K, et al. Phenotype and function of nasal dendritic cells. Mucosal Immunol 2015;8(05):1083-1098

2 Sepahi A, Salinas I. The evolution of nasal immune systems in vertebrates. Mol Immunol 2016;69:131-138

3 Ikincioğullari A, Doğu F, ikincioğullari A, Eğin Y, Babacan E. Is immune system influenced by adenotonsillectomy in children? Int J Pediatr Otorhinolaryngol 2002;66(03):251-257
4 Kaygusuz I, Gödekmerdan A, Karlidag T, et al. Early stage impacts of tonsillectomy on immune functions of children. Int J Pediatr Otorhinolaryngol 2003;67(12):1311-1315

5 Sugiyama M, Sasaki T, Nakai Y, Otani S, Kinoshita Y. Studies on the cell-mediated immune response of tonsillar lymphocytes with regard to the clinical course and patient's age. Int J Pediatr Otorhinolaryngol 1982;4(03):193-208

6 Wlasiuk P, Niedzielski A, Skorka K, et al. Accumulation of $\mathrm{CD}^{+} \mathrm{CD}_{19}{ }^{+}$B lymphocytes expressing PD-1 and PD-1L in hypertrophied pharyngeal tonsils. Clin Exp Med 2016;16(04):503-509

7 Lin E, Calvano SE, Lowry SF. Inflammatory cytokines and cell response in surgery. Surgery 2000;127(02):117-126

8 Geißler K, Markwart R, Requardt RP, et al. Functional characterization of T-cells from palatine tonsils in patients with chronic tonsillitis. PLoS One 2017;12(09):e0183214

9 Zhang JM, An J. Cytokines, inflammation, and pain. Int Anesthesiol Clin 2007;45(02):27-37

10 Curfs JH, Meis JF, Hoogkamp-Korstanje JA. A primer on cytokines: sources, receptors, effects, and inducers. Clin Microbiol Rev 1997; 10(04):742-780

11 Komorowska A, Komorowski J, Banasik M, Lewkowicz P, Tchórzewski H. Cytokines locally produced by lymphocytes removed from the hypertrophic nasopharyngeal and palatine tonsils. Int J Pediatr Otorhinolaryngol 2005;69(07):937-941

12 Nave H, Gebert A, Pabst R. Morphology and immunology of the human palatine tonsil. Anat Embryol (Berl) 2001;204(05):367-373

13 Kim J, Bhattacharjee R, Dayyat E, et al. Increased cellular proliferation and inflammatory cytokines in tonsils derived from children with obstructive sleep apnea. Pediatr Res 2009;66(04):423-428

14 Viswanatha GL, Thippeswamy AH, Rafiq M, et al. Novel experimental model of non-infectious pharyngitis in rats. J Pharmacol Toxicol Methods 2014;69(02):189-195

15 Alcântara LJL, Pereira RG, Mira JGS, et al. Impacto na qualidade de vida nos pacientes adenoamigdalectomizados. Int Arch Otorhinolaryngol 2008;12:172-178

16 Batu ED, Batu HB. Recurrence of periodic fever, aphthous stomatitis, pharyngitis, and cervical adenitis (PFAPA) syndrome after tonsillectomy: case-based review. Rheumatol Int 2019;39(06): 1099-1105

17 Oliveira CMB, Sakata RK, Issy AM, Gerola LR, Salomão R. Citocinas e dor. Rev Bras Anestesiol 2011;61(02):255-265

18 Morris MC, Kozara K, Salamone F, Benoit M, Pichichero ME. Adenoidal follicular $\mathrm{T}$ helper cells provide stronger B-cell help than those from tonsils. Laryngoscope 2016;126(02):E80-E85

19 Passàli D, Damiani V, Passàli GC, Passàli FM, Boccazzi A, Bellussi L. Structural and immunological characteristics of chronically inflamed adenotonsillar tissue in childhood. Clin Diagn Lab Immunol 2004;11(06):1154-1157

20 Bonanomi A, Kojic D, Giger B, et al. Quantitative cytokine gene expression in human tonsils at excision and during histoculture assessed by standardized and calibrated real-time PCR and novel data processing. J Immunol Methods 2003;283(1-2):27-43

21 Foster GE, Poulin MJ, Hanly PJ. Intermittent hypoxia and vascular function: implications for obstructive sleep apnoea. Exp Physiol 2007;92(01):51-65

22 Greenberg H, Ye X, Wilson D, Htoo AK, Hendersen T, Liu SF. Chronic intermittent hypoxia activates nuclear factor-kappaB in cardiovascular tissues in vivo. Biochem Biophys Res Commun 2006;343(02):591-596

23 Agren K, Andersson U, Litton M, Funa K, Nordlander B, Andersson $\mathrm{J}$. The production of immunoregulatory cytokines is localized to the extrafollicular area of human tonsils. Acta Otolaryngol 1996; 116(03):477-485

24 Semberova J, Rychly B, Hanzelova J, Jakubikova J. The immune status in situ of recurrent tonsillitis and idiopathic tonsillar hypertrophy. Bratisl Lek Listy 2013;114(03):140-144 